\title{
Postrelease mortality among persons hospitalized during their incarceration
}

\author{
David L. Rosen, PhD, MD ${ }^{\mathrm{a}, ~ *}$, Andrew L. Kavee, MA ${ }^{\mathrm{b}}$, Lauren Brinkley-Rubinstein, PhD ${ }^{\mathrm{c}, \mathrm{d}}$ \\ a Division of Infectious Diseases, Department of Medicine, School of Medicine, University of North Carolina at Chapel Hill, Chapel Hill \\ ${ }^{\mathrm{b}}$ UNC Cecil G. Sheps Center for Health Services, Chapel Hill, NC \\ ${ }^{c}$ Center for Health Equity Research, School of Medicine, University of North Carolina at Chapel Hill, Chapel Hill \\ ${ }^{\mathrm{d}}$ Department of Social Medicine, School of Medicine, University of North Carolina at Chapel Hill, Chapel Hill
}

\section{A R T I C L E I N F O}

\section{Article history:}

Received 6 June 2019

Accepted 8 March 2020

Available online 2 April 2020

Keywords:

Incarceration release

Mortality

Medicaid

\begin{abstract}
A B S T R A C T
Purpose: Health and mortality of people released from incarceration have received increased attention, and yet little is known about the postrelease experiences of those hospitalized during incarceration. Methods: For persons incarcerated and released from the North Carolina (NC) state prison system between January 1, 2008, and June 30, 2015, we examined postrelease mortality from 2008 to 2016 by history of prison hospitalization.

Results: Among 111,479 released persons, 0.9\% $(n=1010)$ were hospitalized during their incarceration, and of those, $10.5 \%$ ( $n=106)$ died during follow-up compared with $3.2 \%(3511 / 110,469)$ of other released persons. Those hospitalized in prison had a higher postrelease death rate (adjusted hazard ratio: 2.44), a lower 8 -year conditional probability of survival ( $0.80 \mathrm{vs.} 0.94)$, and were more likely to die from chronic causes $(79.2 \%$ vs. $51.0 \%)$ than other released persons. The postrelease standardized mortality rate among men hospitalized in prison was 3.1 times higher than that of those not hospitalized and 7.1 times the rate of all NC men.

Conclusions: People hospitalized during incarceration constitute a particularly vulnerable, yet relatively easily identifiable priority population to focus health interventions supporting continuity of care after prison release. Yet such efforts may be particularly challenging in NC and other Medicaid non-expansion states.
\end{abstract}

\section{Introduction}

Over the past four decades, the U.S. prison population has grown to become the largest in the world [1]. The age distribution of the prison population has also increased over time; between 1993 and 2013, the proportion of imprisoned persons aged 55 years or older increased from $3 \%$ to $10 \%$ [2]. Incarcerated persons often have long histories of behavioral risk factors [3] that lead to poor health outcomes and limited medical care access and use in the communities from which they came [4]. In the context of these

Authors' contributions: D.R. contributed to conceptualization, writing, supervision, and funding acquisition; A.K. contributed to data curation, formal analysis, visualization, and writing, review, and editing the article. L.B.-R. contributed to writing, review, and editing the article.

* Corresponding author. School of Medicine, University of North Carolina at Chapel Hill, 130 Mason Farm Road Campus Box 7030, Chapel Hill, NC 27599. Tel.: +1-919-962-0752; fax: 1-919-966-2723.

E-mail address: drosen@med.unc.edu (D.L. Rosen). demographic, behavioral, and access-to-care factors, it is unsurprising that correctional populations have a heavy burden of disease. According to the most recent national data, $41 \%$ of people incarcerated in a state or federal prison reported having a chronic medical condition [5], and among those aged 50 years or older, $72 \%$ had a chronic condition [5].

U.S. prison systems have a court-affirmed obligation to provide health care to their correctional populations [6]. In general, state prison systems are required to provide at least basic health care within their facilities. But more specialized care or care for high acuity patients may necessitate the use of offsite care, including inpatient stays in community hospitals [7]. At the same time, prison systems' use of community hospitalization may be more expensive than onsite care and represent a substantial proportion of their health care budgets. Existing data from state prisons suggest that community hospitalization consumes at least $20 \%$ of their health care spending [8]. Beyond the direct health care costs, community hospitalization includes costs of staffing correctional officers to 
guard patients for the duration of their hospitalization. In this context, prison systems have a financial incentive to reserve community hospitalization for their highest acuity patients who cannot be cared for adequately onsite. In, to our knowledge, the only published study examining acuity of people who had a community hospitalization during their incarceration, Schneider et al. found that $94 \%$ of community hospitalizations used by the Texas prison system were judged "essential to life and health" (69\%) or "medically necessary" (25\%), reflecting the high level of medical care needed among this population [9].

Although the U.S. prison population has grown and "aged" over the past 4 decades, most incarcerated persons are released back to the community within a few years [2]. Many are without health care coverage upon release-even in Medicaid expansion states- and the transition back to the community can incur increased risk for health problems and for death.

There is a growing body of research to understand mortality risk after prison release. Much of this work has appropriately focused on fatal drug overdose, which is markedly high among people returning from corrections [10-14]. Yet comparatively few studies have examined the mortality outcomes among people with other serious health care needs, including those whose needs were of sufficient acuity to prompt a community hospitalization during their incarceration.

Given high levels of medical acuity among patients who experience community hospitalizations, the substantial cost of these hospitalizations to prison systems, and the difficulty that these formerly incarcerated persons likely experience using health care after their release, we sought to examine mortality among people who experienced a community hospitalization during their incarceration and were subsequently released. We conducted this analysis in the setting of a southern Medicaid nonexpansion state, in which routine access to care after prison release may have been particularly challenging.

\section{Methods}

This project was approved by the University of North Carolina at Chapel Hill Institutional Review Board and by the review board of the North Carolina (NC) state prison system.

\section{Setting}

The NC state prison system is the 12th largest state U.S. prison system [15], consisting of 55 prisons with a daily average population of about 35,000 incarcerated persons and approximately 23,000 entries and exits each year. The prison system operates its own medical system, including a centrally located 120-inpatient bed medical center. For our purposes, hospitalization refers to inpatient stays at community hospitals, which are independent of the prison system. Authorization of these hospitalizations are provided by the prison systems' Health Services Utilization Management Section, which determines-based on medical necessity, appropriate level of care, appropriate setting, and other factors-whether an incarcerated person requires a community hospitalization.

\section{Data sources}

We received individual-level records from the prison system for all people aged 18 years or older who entered prison anytime from 2008 to 2014. Records included identifiers (names and date of birth and social security number [SSN]), demographic characteristics (sex, race, and ethnicity), dates of entry and exit, and indicators for the setting and dates of any health care provided outside of the prison system. We classified as community inpatient hospitalizations the delivery of health care at a community hospital in which the length of care spanned more than one calendar day. We created a dichotomous variable to represent any versus no community inpatient hospitalizations during imprisonment. We also received an additional data set from the prison system, allowing us to identify reincarcerations through 2016.

We received individual-level death records from the NC State Center for Health Statistics for the years 2008-2016. Records included names, dates of birth, SSN, and the International Classification of Disease version 10 code indicating primary cause of death (COD). To facilitate analysis, we used the Agency for HealthCare Research and Quality's Clinical Classification Software (CCS) to collapse the International Classification of Disease COD codes into 12 main categories and 18 subcategories. We created an additional category for "chronic" conditions, which included all causes of death except for causes classified as "external" (e.g., homicides, poisonings, and motor vehicle accidents) and self-harm codes listed under the category "mental health."

We conducted record linkage using SAS version 9.4 and the Link King software version 9.0, which integrates deterministic matching algorithms with probabilistic matching routines. We used names, dates of birth, and SSN to match death and prisoner records. As a conservative approach, we only accepted as true matches record pairs classified as Level 1 Certainty ("definite match") by the linking software [16]. We then removed all personal identifiers to create our analytic data set. We also excluded 173 people $(0.2 \%)$ with a date of death before prison exit.

\section{Analysis}

We designated the first incarceration as our index incarceration, for which we based our analyses. Among index incarcerations, we examined the distribution of demographic and incarceration characteristics among people incarcerated and released from the prison system anytime between January 1, 2008, and June 30, 2015. We estimated the rate of community hospitalization during the index incarceration estimating incarceration follow-up as number of days between prison entry and release, and we compared the characteristics of people experiencing any of these hospitalizations with the characteristics of those who did not. For the entire population and stratified by hospitalization history, we examined the distribution of primary CODs. We calculated postrelease follow-up time as the number of days between release from the index incarceration and whichever occurred first: death, another incarceration or December 31, 2016. Using this follow-up time, we examined crude rates for each COD category and subcategory, stratified by hospitalization status. Using the demographic composition of the NC resident population, we estimated standardized all-cause mortality rates by prison hospitalization history. We limited this analysis to the $99.9 \%$ of people aged 69 years or younger in our study population. Standardization was conducted accounting for age group $(18-29,30-39, \ldots, 60-69$ years), sex (male and female), and race (White, Black, and Other).

We used Kaplan-Meier failure curves to examine the postrelease distribution of time until death or censoring for all released persons and stratified by hospitalization history. We also developed Cox proportional hazard models to examine the relationship between a history of prison hospitalization and postrelease all-cause mortality. To adjust for measured confounding, our model included the independent variables age, gender, race, and year of prison release. 


\section{Results}

During the study period, 111,479 unique individuals were released from the prison system, with an aggregate follow-up time of 471,282 person-years. Among our study population, $0.9 \%(n=1010)$ had a community hospitalization during their first incarceration (Table 1), and the rate of hospitalization was 13.9 per 1000. Compared with formerly incarcerated persons without a hospitalization, those with hospitalizations were significantly more likely to be White, female, released later in the study period, older, have served longer sentences, and were more likely to have been convicted of a sex-related offense or "other" type of offense, which excluded those for violence, property, or drug use (Table 1).
Among all people released from prison, 3.2\% $(n=3617)$ died during follow-up, resulting in a crude mortality rate of 767.5 per 100,000 . Among those with a history of hospitalization, $10.5 \%$ $(n=106)$ died, for a crude mortality rate of 2635.5 deaths per 100,000 . Among people with a history of prison hospitalization, the most common major categories of death were circulatory conditions (23.6\%), including heart disease (18.9\%), external causes (19.8\%) including poisonings (15.1\%), and neoplasms (17.0\%; Table 2). Overall, 79\% of deaths among previously incarcerated hospitalized persons were from chronic causes. In contrast, among formerly incarcerated persons without prison hospitalization, 3.2\% died, resulting in a crude mortality rate of 751.4 per 100,000 . The most common causes of death among nonhospitalized persons included external causes (44.6\%), including poisonings (19.1\%),

Table 1

Characteristics of adults released from the North Carolina state prison system from 2008 to 2015, by hospitalization status during incarceration

\begin{tabular}{|c|c|c|c|c|c|c|c|}
\hline & \multirow{2}{*}{\multicolumn{2}{|c|}{ Total }} & \multicolumn{5}{|c|}{ Hospitalized during incarceration ${ }^{*}$} \\
\hline & & & \multicolumn{2}{|l|}{ Yes } & \multicolumn{2}{|l|}{ No } & \multirow[t]{2}{*}{$P^{\dagger}$} \\
\hline & $n$ & $\%$ & $n$ & $\%$ & $n$ & $\%$ & \\
\hline Total & 111,479 & - & 1010 & - & 110,469 & - & \\
\hline Race & & & & & & & $<.0001$ \\
\hline Black, non-Hispanic & 56,155 & 50.4 & 442 & 43.7 & 55,713 & 50.4 & \\
\hline White, non-Hispanic & 46,618 & 41.8 & 503 & 49.8 & 46,115 & 41.7 & \\
\hline Other, unknown non-Hispanic & 2968 & 2.7 & 35 & 3.5 & 2933 & 2.7 & \\
\hline Hispanic & 5738 & 5.1 & 30 & 3.0 & 5708 & 5.2 & \\
\hline Gender & & & & & & & $<.0001$ \\
\hline Female & 15,112 & 13.6 & 334 & 33.1 & 14,778 & 13.4 & \\
\hline Male & 96,367 & 86.4 & 676 & 66.9 & 95,691 & 86.6 & \\
\hline Prison entry $(y)$ & & & & & & & $<.0001$ \\
\hline 2008 & 26,108 & 23.4 & 302 & 29.9 & 25,806 & 23.4 & $<.0001$ \\
\hline 2009 & 23,601 & 21.2 & 198 & 19.6 & 23,403 & 21.2 & $<.0001$ \\
\hline 2010 & 19,885 & 17.8 & 172 & 17.0 & 19,713 & 17.8 & $<.0001$ \\
\hline 2011 & 17,188 & 15.4 & 157 & 15.6 & 17,031 & 15.4 & $<.0001$ \\
\hline 2012 & 10,187 & 9.2 & 83 & 8.2 & 10,104 & 9.2 & $<.0001$ \\
\hline 2013 & 8370 & 7.5 & 65 & 6.4 & 8305 & 7.5 & $<.0001$ \\
\hline 2014 & 6140 & 5.5 & 33 & 3.3 & 6107 & 5.5 & $<.0001$ \\
\hline Prison exit (y) & & & & & & & $<.0001$ \\
\hline 2008 & 12,163 & 10.9 & 84 & 8.3 & 12,079 & 10.9 & $<.0001$ \\
\hline 2009 & 21,283 & 19.1 & 141 & 14.0 & 21,142 & 19.2 & $<.0001$ \\
\hline 2010 & 20,277 & 18.2 & 162 & 16.0 & 20,115 & 18.2 & $<.0001$ \\
\hline 2011 & 19,073 & 17.1 & 172 & 17.0 & 18,901 & 17.1 & $<.0001$ \\
\hline 2012 & 13,546 & 12.2 & 138 & 13.7 & 13,408 & 12.1 & $<.0001$ \\
\hline 2013 & 10,915 & 9.8 & 122 & 12.1 & 10,793 & 9.8 & $<.0001$ \\
\hline 2014 & 10,285 & 9.2 & 143 & 14.2 & 10,142 & 9.2 & $<.0001$ \\
\hline 2015 & 3937 & 3.5 & 48 & 4.7 & 3889 & 3.5 & $<.0001$ \\
\hline Age at entry (y) & & & & & & & $<.0001$ \\
\hline $18-24$ & 28,907 & 25.9 & 154 & 15.3 & 28,753 & 26.0 & \\
\hline $25-30$ & 24,009 & 21.5 & 154 & 15.3 & 23,855 & 21.6 & \\
\hline $31-40$ & 29,514 & 26.5 & 225 & 22.3 & 29,289 & 26.5 & \\
\hline $41-87$ & 29,049 & 26.1 & 477 & 47.2 & 28,572 & 25.9 & \\
\hline Age at exit (y) & & & & & & & $<.0001$ \\
\hline $18-24$ & 25,508 & 22.9 & 117 & 11.6 & 25,391 & 23.0 & \\
\hline $25-30$ & 24,459 & 21.9 & 157 & 15.5 & 24,302 & 22.0 & \\
\hline $31-40$ & 30,373 & 27.3 & 222 & 22.0 & 30,151 & 27.3 & \\
\hline $41-88$ & 31,139 & 27.9 & 514 & 50.9 & 30,625 & 27.7 & \\
\hline Sentence length (mo) & & & & & & & $<.0001$ \\
\hline Quartile (q) $1(0-5 \mathrm{mo})$ & 26,369 & 23.7 & 104 & 10.3 & 26,265 & 23.8 & \\
\hline $\mathrm{q} 2(6-10)$ & 27,955 & 25.1 & 212 & 21.0 & 27,743 & 25.1 & \\
\hline q3 $(11-21)$ & 28,924 & 25.9 & 233 & 23.1 & 28,691 & 26.0 & \\
\hline $\mathrm{q} 4(22-12,258)$ & 28,219 & 25.3 & 461 & 45.6 & 27,758 & 25.1 & \\
\hline Crime category & & & & & & & $<.0001$ \\
\hline Violent & 19,089 & 17.2 & 172 & 17.1 & 18,917 & 17.2 & \\
\hline Sex & 3864 & 3.5 & 60 & 5.9 & 3804 & 3.4 & \\
\hline Property & 26,891 & 24.2 & 172 & 17.1 & 26,719 & 24.3 & \\
\hline Drugs/alcohol & 40,602 & 36.5 & 374 & 37.1 & 40,228 & 36.5 & \\
\hline Other types of crimes & 20,718 & 18.6 & 231 & 22.9 & 20,487 & 18.6 & \\
\hline
\end{tabular}

${ }^{*}$ Defined as any external health care admissions with service length spanning at least two consecutive days.

+ Comparing row percentages $\left(\chi^{2}\right.$ probability of general association; $\mathrm{df}=$ rows -1$)$.

$\ddagger$ Excludes 12 prisoners without a sentence length.

$\S$ Excludes 315 prisoners without a crime category code. 
Table 2

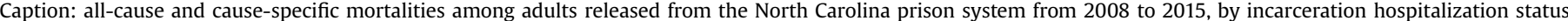
$(n=111,479)$

\begin{tabular}{|c|c|c|c|c|c|c|c|c|c|}
\hline & \multicolumn{3}{|l|}{ All } & \multicolumn{3}{|c|}{$\begin{array}{l}\text { Hospitalized during } \\
\text { incarceration }\end{array}$} & \multicolumn{3}{|c|}{$\begin{array}{l}\text { Not hospitalized during } \\
\text { incarceration }\end{array}$} \\
\hline & $n$ & $\%$ & Rate $^{* \dagger}$ & $n$ & $\%$ & Rate ${ }^{* \dagger}$ & $n$ & $\%$ & Rate $^{*, \dagger}$ \\
\hline All & 3617 & 100.0 & 767.5 & 106 & 100.0 & 2635.5 & 3511 & 100.0 & 751.4 \\
\hline Chronic diseases & 1875 & 51.8 & 397.9 & 84 & 79.2 & 2088.5 & 1791 & 51.0 & 383.3 \\
\hline Infectious and parasitic diseases & 173 & 4.8 & 36.7 & 5 & 4.7 & 124.3 & 168 & 4.8 & 36.0 \\
\hline HIV infection & 67 & 1.9 & 14.2 & 3 & 2.8 & 74.6 & 64 & 1.8 & 13.7 \\
\hline Hepatitis & 57 & 1.6 & 12.1 & 2 & 1.9 & 49.7 & 55 & 1.6 & 11.8 \\
\hline Hepatitis C & 48 & 1.3 & 10.2 & 1 & 0.9 & 24.9 & 47 & 1.3 & 10.1 \\
\hline Neoplasms & 474 & 13.1 & 100.6 & 18 & 17.0 & 447.5 & 456 & 13.0 & 97.6 \\
\hline Colorectal cancer & 38 & 1.1 & 8.1 & 0 & 0.0 & - & 38 & 1.1 & 8.1 \\
\hline Cancer of bronchus, lung & 146 & 4.0 & 31.0 & 6 & 5.7 & 149.2 & 140 & 4.0 & 30.0 \\
\hline $\begin{array}{l}\text { Endocrine, nutritional, and metabolic diseases } \\
\text { and immunity disorders }\end{array}$ & 105 & 2.9 & 22.3 & 5 & 4.7 & 124.3 & 100 & 2.8 & 21.4 \\
\hline Diabetes mellitus & 70 & 1.9 & 14.9 & 5 & 4.7 & 124.3 & 65 & 1.9 & 13.9 \\
\hline Diseases of the blood and blood-forming organs & 14 & 0.4 & 3.0 & 2 & 1.9 & 49.7 & 12 & 0.3 & 2.6 \\
\hline Mental illness & 359 & 9.9 & 76.2 & 10 & 9.4 & 248.6 & 349 & 9.9 & 74.7 \\
\hline Alcohol and substance-related disorders & 172 & 4.8 & 36.5 & 6 & 5.7 & 149.2 & 166 & 4.7 & 35.5 \\
\hline Suicide and intentional self-inflicted injury & 179 & 4.9 & 38.0 & 3 & 2.8 & 74.6 & 176 & 5.0 & 37.7 \\
\hline Diseases of the nervous system and sense organs & 47 & 1.3 & 10.0 & 2 & 1.9 & 49.7 & 45 & 1.3 & 9.6 \\
\hline Diseases of the circulatory system & 566 & 15.6 & 120.1 & 25 & 23.6 & 621.6 & 541 & 15.4 & 115.8 \\
\hline Diseases of the heart & 392 & 10.8 & 83.2 & 20 & 18.9 & 497.3 & 372 & 10.6 & 79.6 \\
\hline Cerebrovascular disease & 79 & 2.2 & 16.8 & 5 & 4.7 & 124.3 & 74 & 2.1 & 15.8 \\
\hline Diseases of the respiratory system ${ }^{\S}$ & 123 & 3.4 & 26.1 & 7 & 6.6 & 174.0 & 116 & 3.3 & 24.8 \\
\hline Chronic obstructive pulmonary disease and bronchiectasis & 71 & 2.0 & 15.1 & 5 & 4.7 & 124.3 & 66 & 1.9 & 14.1 \\
\hline Asthma & 4 & 0.1 & 0.8 & 0 & 0.0 & - & 4 & 0.1 & 0.9 \\
\hline Diseases of the digestive system & 116 & 3.2 & 24.6 & 6 & 5.7 & 149.2 & 110 & 3.1 & 23.5 \\
\hline Liver disease & 78 & 2.2 & 16.6 & 4 & 3.8 & 99.5 & 74 & 2.1 & 15.8 \\
\hline Diseases $10-15$ & 53 & 1.5 & 11.2 & 5 & 4.7 & 124.3 & 48 & 1.4 & 10.3 \\
\hline $\begin{array}{l}\text { Symptoms, signs, and ill-defined conditions and factors } \\
\text { influencing health status }\end{array}$ & 1 & 0.0 & 0.2 & 0 & 0.0 & - & 1 & 0.0 & 0.2 \\
\hline Residual codes, unclassified, and all external codes $\|$ & 1586 & 43.8 & 336.5 & 21 & 19.8 & 522.1 & 1565 & 44.6 & 334.9 \\
\hline Motor vehicle traffic & 325 & 9.0 & 69.0 & 1 & 0.9 & 24.9 & 324 & 9.2 & 69.3 \\
\hline $\begin{array}{l}\text { Homicide and injury purposely inflicted by } \\
\text { other persons ((E960-E969) }\end{array}$ & 395 & 10.9 & 83.8 & 4 & 3.8 & 99.5 & 391 & 11.1 & 83.7 \\
\hline Poisoning & 688 & 19.0 & 146.0 & 16 & 15.1 & 397.8 & 672 & 19.1 & 143.8 \\
\hline Poisoning except suicide and homicide & 663 & 18.3 & 140.7 & 14 & 13.2 & 348.1 & 649 & 18.5 & 138.9 \\
\hline Opioid poisoning (illicit and prescription) & 460 & 12.7 & 97.6 & 8 & 7.5 & 198.9 & 452 & 12.9 & 96.7 \\
\hline
\end{tabular}

${ }^{*}$ Death rate $=$ number of deaths divided by total postrelease survival time per 100,000 person-years.

$\dagger$ Total follow-up time (471,282 person-years) and follow-up time among those ever hospitalized (4022 person-years) and not (467,260 person-years).

$\ddagger$ Chronic diseases-infectious and parasitic diseases, neoplasms, endocrine; nutritional; and metabolic diseases and immunity disorders, diseases of the blood and blood-

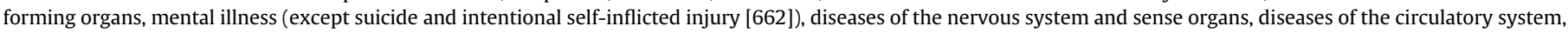

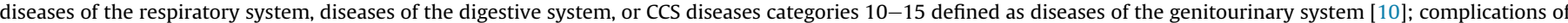

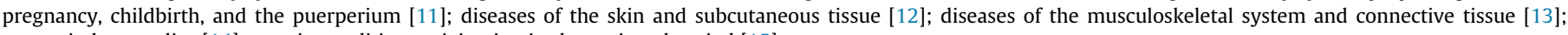
congenital anomalies [14]; certain conditions originating in the perinatal period [15].

$\S$ Includes one prisoner matching via Link King Certainty 1, ever released, but lack a primary COD value (ICD-10 code of J09-“Influenza due to certain identified influenza viruses").

$\|$ Includes 16 prisoners matching via Link King Certainty 1, ever released, but lack a primary COD value.

" Opioid poisoning (illicit and prescription)-underlying primary poisoning and secondary contributing opioid CODs.

circulatory problems (15.4\%), and neoplasms (13.0\%). Overall, 51\% among nonhospitalized persons were attributable to chronic health conditions.

The age-, race-, and sex-standardized all-cause mortality rate among hospitalized persons was 2405.0 per 100,000 and among nonhospitalized persons was 1026.2 per 100,000 . Among men, the standardized mortality rates among those hospitalized and not hospitalized were 3949 and 1267 per 100,00, whereas among women, they were 930 and 796 per 100,000, respectively.

Examining the Kaplan-Meier failure curves for people released from prison, the probability of death was statistically greater across the study period $(\log$-rank $P<.001)$ for those with a history of hospitalization. Based on the Kaplan-Meier curves, the conditional probability of survival was 0.97 and 0.80 at Years 1 and 8 among those with a history of hospitalization and 0.99 and 0.94 at Years 1 and 8 among those with a history of no hospitalization (Fig. 1).

The unadjusted and adjusted hazard ratios for mortality among those who had been hospitalized during prison compared with other incarcerated persons was 3.54 (95\% confidence interval, 2.92-4.29) and 2.44 (95\% confidence interval, 2.01-2.96; Table 3).

\section{Discussion}

When incarcerated persons are released from prison and return to their communities, they often face an array of economic and social challenges [17]. Those returning citizens who have serious health conditions have the additional burden of accessing and paying for health care [4,18] — and lack of care can result in greater morbidity and mortality. In this study, we examined the postrelease mortality among people who had a community hospitalization during their imprisonment. We found that, compared with other released persons, those hospitalized during incarceration were at elevated risk of death and overwhelmingly died from chronic health conditions.

During incarceration, about $1 \%$ of our population experienced a community inpatient hospitalization during incarceration. This percentage is generally aligned with our derived estimate from the 


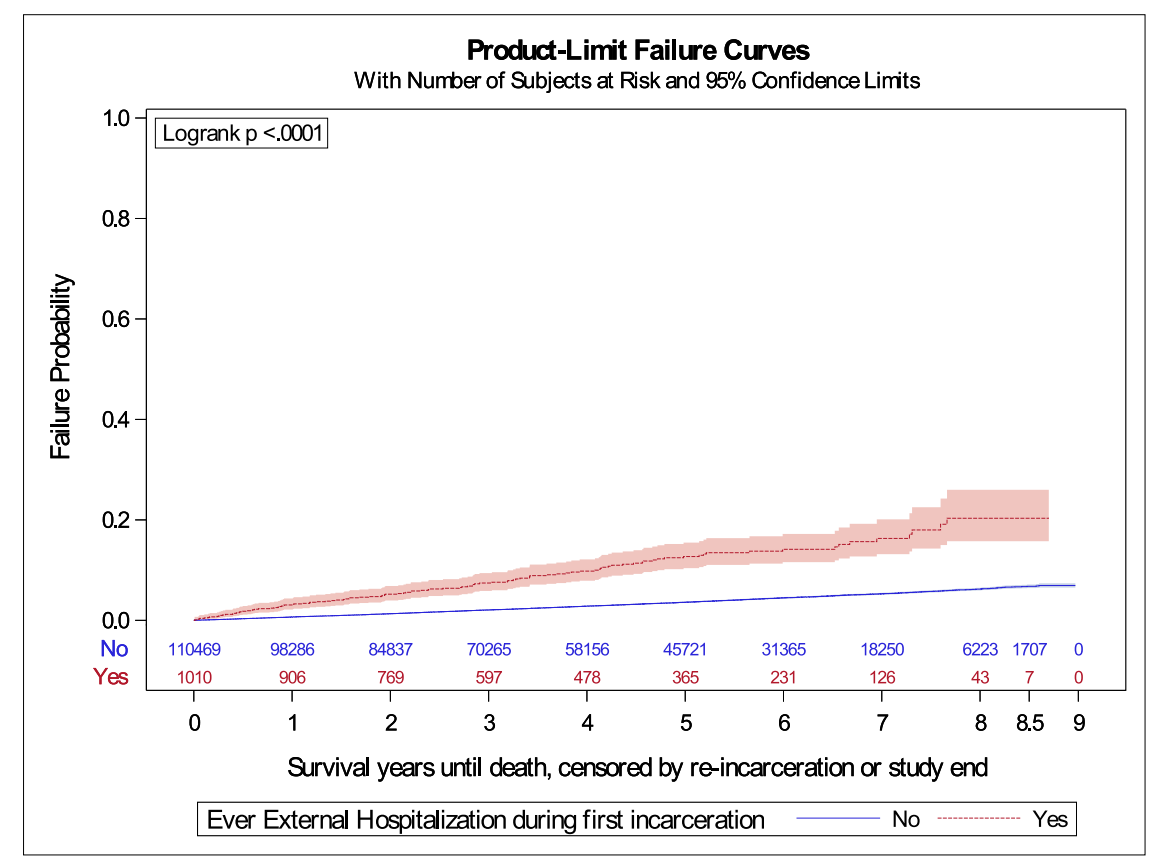

Fig. 1. Product-limit failure curves.

Source: authors' analysis of data from the NC state prison system (2008-2015) and NC State Center for Health Statistics (2008-2016).

Schneider et al.'s study, which analyzed community hospitalization use by the Texas prison system [9]. And yet hospitalization rates among our correctional study population (13.9 per 1000) were about one-sixth to one-eighth the rates among 18- to 64-year-olds in the general U.S. population [19]. The relative rarity of community hospitalizations among our population of incarcerated persons corroborates our supposition that hospitalizations during incarceration were largely reserved for high acuity patients, many of whom would require postrelease health care.

In our study, those with community hospitalizations were older and more likely to be White than other incarcerated persons. These findings are aligned with other studies of correctional populations, reporting that incarcerated Whites tend to have a heavier burden of health care needs than people who identify in other racial groups $[20,21]$. This dynamic may reflect the overrepresentation of people of color in the criminal justice setting; in this context, Whites who do become incarcerated may have a particularly high level of sociobehavioral, economic need, which is reflected by their excess health problems. An alternative explanation is that Whites had greater access to health care, similar to patterns seen in the general population. We also found that women were more likely than men to be hospitalized, a result congruent with nationally representative studies finding greater burden of disease among incarcerated women compared with men [22,23].

Overall, more than one in 10 people who were hospitalized during the index incarceration died during the follow-up period, compared with about one in every 31 nonhospitalized persons. After standardizing by age, race, and sex, the mortality rate among those hospitalized was 2.3 times as high as the rate among those not hospitalized and greater than 5 times the mortality rate among

Table 3

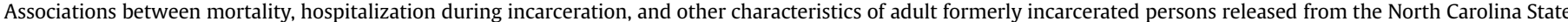
prison system from 2008 to $2015(n=111,479)$

\begin{tabular}{|c|c|c|c|c|c|}
\hline \multirow[t]{2}{*}{ Characteristics } & \multirow[t]{2}{*}{ Level } & \multicolumn{2}{|l|}{ Unadjusted } & \multicolumn{2}{|l|}{ Adjusted } \\
\hline & & $\mathrm{HR}(95 \% \mathrm{CI})$ & $P$ & $\mathrm{HR}(95 \% \mathrm{CI})$ & $P$ \\
\hline \multicolumn{2}{|c|}{ Ever hospitalized during index incarceration* } & $3.54(2.92-4.29)$ & $<.0001$ & $2.44(2.01-2.96)$ & $<.0001$ \\
\hline \multicolumn{2}{|l|}{ Female** } & $0.82(0.74-0.90)$ & $<.0001$ & $0.74(0.67-0.81)$ & $<.0001$ \\
\hline \multicolumn{2}{|c|}{ Age at release ( $1 \mathrm{y}$ increase) } & $1.06(1.06-1.06)$ & $<.0001$ & $1.061 .06-1.06)$ & $<.0001$ \\
\hline \multirow[t]{3}{*}{ Race } & Black & $2.55(2.06-3.16)$ & $<.0001$ & $2.06(1.66-2.55)$ & $<.0001$ \\
\hline & White & $4.46(3.61-5.52)$ & $<.0001$ & $3.64(2.95-4.51)$ & $<.0001$ \\
\hline & Indian/Asian/other/unknown & 1 & & 1 & \\
\hline \multicolumn{6}{|l|}{ Year of release } \\
\hline & 2008 & 1 & & 1 & \\
\hline & 2009 & $0.93(0.83-1.03)$ & .176 & $0.93(0.83-1.04)$ & .184 \\
\hline & 2010 & $0.97(0.86-1.09)$ & .588 & $0.96(0.86-1.08)$ & .541 \\
\hline & 2011 & $1.01(0.89-1.13)$ & .92 & $1(0.89-1.13)$ & .946 \\
\hline & 2012 & $1.01(0.88-1.16)$ & .872 & $0.99(0.86-1.13)$ & .853 \\
\hline & 2013 & $1.09(0.93-1.27)$ & .293 & $1.02(0.87-1.19)$ & .817 \\
\hline & 2014 & $1.2(1.01-1.43)$ & .041 & $1.07(0.89-1.27)$ & .482 \\
\hline & 2015 (through June 30) & $0.98(0.71-1.36)$ & .923 & $0.84(0.61-1.17)$ & .309 \\
\hline
\end{tabular}

$\mathrm{CI}=$ confidence interval; HR $=$ hazard ratio.

Reference level: *Never hospitalized during index incarceration. **Male. 
persons in the general state population ( 2163 vs. 452 per 100,000$)$ [24]. Mortality among hospitalized men was greater than three times that of those not hospitalized and greater than seven times that of general population males (3949 vs. 558 per 100,000) [24]. For all hospitalized persons, deaths were predominantly from chronic health conditions and occurred at a steady rate for several years after release, suggesting that many who were hospitalized during incarceration have long periods requiring disease management.

Yet as a Medicaid nonexpansion state, there are few options to continue health care for low-income people re-entering the community. Despite a prison-based program that facilitates Medicaid enrollment (based on nonexpansion eligibility criteria) to pay for community hospitalization during incarceration [25], some qualitative evidence suggests that there may be substantial barriers to retaining and continuing Medicaid enrollment postrelease [18]. And only a small proportion of those hospitalized in our study $(<3 \%)$ were old enough to eligible for Medicare.

Although prison system policy is to provide a medical referral to released prisoners who have chronic conditions, patients' followup is likely limited by inadequate access to routine care and competing priorities such as substance use recovery and establishing housing and employment [4,26]. Existing research suggests that people released from prison rely heavily on emergency departments (EDs) for health care. For example, about one-fourth of people released from the Rhode Island correctional system had an ED visit within the following year [27], and in a study of HIVpositive persons leaving the Connecticut correctional system, 56\% had an ED visit in the following year [28]. Limited continuity of routine care, as reflected by heavy ED use, not only portends poor health outcomes among released persons but also suggests that prison systems' sizable financial investment in health care during incarceration will have at best a modest impact on long-term, postrelease health. In NC, the prison system spends $\$ 250$ million in health care annually [7], of which, we estimate $\$ 50$ million is spent on hospitalizations [8]. Greater investment in continuity of care to complement health care spending during incarceration could potentially reduce postrelease ED overutilization and improve health and longevity.

One mechanism to support continuity of care is the Transitions Clinic Model [29]. This model, which has been implemented in 11 states and Puerto Rico and was recently established in NC, uses community health workers with an incarceration history to facilitate returning citizens' linkage to and retention in a community health clinic. There are four transition clinics currently in NC, but further expansion is needed to provide coverage for the 23,000 people annually released from the state prison system, one-third of which are conservatively estimated to have chronic health problems [30]. Such an expansion would likely require not only expanded Medicaid eligibility but also state and local dollars to support the clinics and community health workers.

Deaths among those who had not been hospitalized were most commonly from accidents including poisoning, which is commonly referred to as drug overdose. Although these patterns were not unexpected [11], it could be misleading to think of risk among nonhospitalized and hospitalized persons as discrete, as nearly half of people without a hospitalization died from chronic health problems, and $15 \%$ of those with a hospitalization died from drug overdose. Notably, deaths attributable to heroin overdose could be greatly diminished with greater access to appropriate medications, such as buprenorphine, during incarceration and at release [31]. More generally, the increased mortality rate among those who were hospitalized and the relatively small size of this population compared with other incarcerated persons suggest that it could be feasible to identify and prioritize this population for more robust postrelease services. Our findings suggest that such prioritization is particularly needed for men who experience hospitalization during incarceration consideration their disproportionately high death rates and limited eligibility for Medicaid.

This study has some limitations. First, we did not have information on the entire prison population but rather a cohort of people who entered from 2008 to 2014 . Accordingly, the number of deaths in our study does not represent the total number of deaths among people released from the prison system during this period. Second, our data did not include information on postrelease health or health care nor did it include hospitalization reason during incarceration. Accordingly, people hospitalized during their incarceration may not have necessarily had major health needs from the time of the release to the time of their death. This was likely true among women more often than for men. Finally, the NC prison system has its own onsite medical center and thus may use outside hospitalizations less frequently and for higher acuity patients than other state prison systems.

In conclusion, we found that more than one in 10 people hospitalized during their imprisonment died in the postrelease period resulting in a standardized mortality rate 2.3 times as high as that of other released persons. And yet few deaths among this population occurred soon after release, suggesting that many of these people had long periods of substantial health care need when in the community. Given high mortality rates among this population-and substantial financial resources that prison systems invest in these patients' hospitalizations-people hospitalized during incarceration may constitute a relatively easily identifiable, priority population to focus health interventions fostering greater continuity of postrelease care. However, interventions will likely require an expansion of Medicaid eligibility as well as funding support at the state and local levels.

\section{Acknowledgments}

Research reported in this publication was supported by the National Institute on Minority Health and Health Disparities, United States of the National Institutes of Health under Award Number R01MD008979. The content is solely the responsibility of the authors and does not necessarily represent the official views of the National Institutes of Health.

\section{References}

[1] Walmsley R. World prison population list, eleventh edition. 2006. http:// prisonstudies.org/sites/default/files/resources/downloads/world_prison_popu lation_list_11th_edition_0.pdf. [Accessed 17 April 2020].

[2] Carson EA, Sabol WJ. Aging of the state prison population, 1993-2013. Washington, DC: US Department of Justice, Bureau of Justice Statistics; 2016. Report No.: NCJ 248766.

[3] Mumola CJ, Karberg JC. Drug use and dependence, state and federal prisoners, 2004. Washington, DC: US Department of Justice, Bureau of Justice Statistics; 2006. Report No.: NCJ 213530.

[4] Mallik-Kane K, Visher CA. Health and prisoner reentry: how physical, mental, and substance abuse conditions shape the process of reintegration. Washington, DC: Urban Institue; 2008.

[5] Maruschak LM, Berzofsky M, Unangst J. Medical problems of state and federal prisoners and jail inmates, 2011-12. Washington, DC: US Department of Justice, Bureau of Justice Statistics; 2015. Report No.: NCJ 248491.

[6] Estelle vs, gamble. U.S. Supreme Court; 1976. p. 429.

[7] Pew Charitable Trusts. Prison health care: costs and quality. How and why states strive for high-performing systems. 2017. https://www.pewtrusts.org/\% 7E/media/assets/2017/10/sfh_prison_health_care_costs_and_quality_final. pdf. [Accessed 17 April 2020].

[8] Pew Charitable Trusts, John D, Cathertine T. MacArthur Foundation. State prison health care spending. 2014. http://www.pewtrusts.org/ /media/assets/ 2014/07/stateprisonhealthcarespendingreport.pdf. [Accessed 17 April 2020].

[9] Schneider BC, Harzke AJ, Ivanitskaya L, Murray OJ. Prioritization of inpatient hospital services to prisoners: a method for justifying care and costs. J Health Care Poor Underserved 2014;25(2):863-76. 
[10] Binswanger IA, Stern MF, Deyo RA, Heagerty PJ, Cheadle A, Elmore JG, et al. Release from prison-a high risk of death for former inmates. N Engl J Med 2007;356(2):157-65.

[11] Ranapurwala SI, Shanahan ME, Alexandridis AA, Proescholdbell SK, Naumann RB, Edwards Jr D, et al. Opioid overdose mortality among former North Carolina inmates: 2000-2015. Am J Public Health 2018;108(9):1207-13.

[12] Binswanger IA, Blatchford PJ, Mueller SR, Stern MF. Mortality after prison release: opioid overdose and other causes of death, risk factors, and time trends from 1999 to 2009. Ann Intern Med 2013:159(9):592-600.

[13] Chang Z, Lichtenstein P, Larsson H, Fazel S. Substance use disorders, psychiatric disorders, and mortality after release from prison: a nationwide longitudinal cohort study. Lancet Psychiatry 2015;2(5):422-30.

[14] Gjersing L, Bretteville-Jensen AL. Gender differences in mortality and risk factors in a 13-year cohort study of street-recruited injecting drug users. BMC Public Health 2014;14:440.

[15] Carson EA. Prisoners in 2016. Washington, DC: US Department of Justice Bureau of Justice Statistics; 2018. Report No.: NCJ 251149.

[16] Campell K, Deck D, Cox A, Broderick C. The link king user manual: Version v5.2. 2006. http://www.the-link-king.com|user_manual.zip. [Accessed 6 June 2014].

[17] La Vigne NG, Kachnowski V, Travis J, Naser R, Visher C. A portrait of prisoner reentry in Maryland. Washington, D.C.: The Urban Institute; 2003.

[18] Grodensky CA, Rosen DL, Blue CM, Miller AR, Bradley-Bull S, Powell WA, et al. Medicaid enrollment among prison inmates in a non-expansion state: exploring predisposing, enabling, and need factors related to enrollment preincarceration and post-release. J Urban Health 2018;95(4):454-66.

[19] Weiss AJ, Elixhauser A. Overview of hospital stays in the United States, 2012. 2014 https://www.hcup-us.ahrq.gov/reports/statbriefs/sb180-Hospitalizations-Unit ed-States-2012.pdf. [Accessed 17 April 2020].

[20] Rosen DL, Hammond WP, Wohl DA, Golin CE. Disease prevalence and use of health care among a national sample of black and white male state prisoners. J Health Care Poor Underserved 2012;23(1):254-72.

[21] Teplin LA, Abram KM, McClelland GM, Dulcan MK, Mericle AA. Psychiatric disorders in youth in juvenile detention. Arch Gen Psychiatry 2002;59(12): 1133-43.
[22] Binswanger IA, Merrill JO, Krueger PM, White MC, Booth RE, Elmore JG. Gender differences in chronic medical, psychiatric, and substancedependence disorders among jail inmates. Am J Public Health 2010;100(3): 476-82.

[23] Nowotny KM. Social factors related to the utilization of health care among prison inmates. I Correct Health Care 2016;22(2):129-38.

[24] Underlying Cause of Death 1999-2018 on CDC WONDER Online Database. Data are from the multiple cause of death files, 1999-2018, as compiled from data provided by the 57 vital statistics jurisdictions through the Vital Statistics Cooperative Program. Estimated rates are based on deaths in NC among those aged 18-69 years for calendar years 2008-2016. 2020. http://wonder.cdc.gov/ ucd-icd10.html. [Accessed 14 February 2020].

[25] Rosen DL, Grodensky CA, Miller AR, Golin CE, Domino ME, Powell W, et al. Implementing a prison medicaid enrollment program for inmates with a community inpatient hospitalization. J Urban Health 2018;95(2):149-58.

[26] Dong KR, Must A, Tang AM, Beckwith CG, Stopka T]. Competing priorities that rival health in adults on probation in Rhode Island: substance use recovery, employment, housing, and food intake. BMC Public Health 2018;18:289.

[27] Frank JW, Andrews CM, Green TC, Samuels AM, Trinh TT, Friedmann PD Emergency department utilization among recently released prisoners: a retrospective cohort study. BMC Emerg Med 2013;13:16.

[28] Meyer JP, Qiu J, Chen NE, Larkin GL, Altice FL. Emergency department use by released prisoners with HIV: an observational longitudinal study. PLoS One 2012;7(8):e42416.

[29] Wang EA, Hong CS, Samuels L, Shavit S, Sanders R, Kushel M. Transitions clinic: creating a community-based model of health care for recently released California prisoners. Public Health Rep 2010;125(2):171-7.

[30] Ashkin E, Rosen DL, Thomas S, Ashkin ERD, Thomas S, Kavee AL, et al. Determination of disease prevalence in recently released prisoners from the North Carolina state prison system using pharmacy data. 12th Academic and Health Policy on Conference on Correctional Health; Las Vegas, NV. 2019.

[31] Green TC, Clarke J, Brinkley-Rubinstein L, Marshall BDL, Alexander-Scott N Boss R, et al. Postincarceration fatal overdoses after implementing medications for addiction treatment in a statewide correctional system. JAMA Psychiatry 2018;75(4):405-7. 